\title{
EDUCAÇÃO E TRABALHO E FINANCIAMENTO DA EDUCAÇÃO PROFISSIONAL NO BRASIL: UM MAPEAMENTO DA PRODUÇÃO DO CONHECIMENTO
}

\author{
Ramon Igor da Silveira Oliveira*, Maria Aparecida dos Santos Ferreira \\ *E-mail: ramonygor@hotmail.com \\ Instituto Federal de Educação, Ciência e Tecnologia do Rio Grande do Norte
}

DOI: 10.15628/rbept.2020.11255

Artigo submetido em: set/2020 e aceito em: nov/2020

\section{RESUMO}

O presente estudo tem como objetivo analisar e quantificar a produção do conhecimento em educação e trabalho e financiamento da educação profissional, em Programas de PósGraduação. Para tanto, fez-se um mapeamento da produção através da Biblioteca Digital Brasileira de Teses e Dissertações, realizando-se consultas a partir do campo "assunto". É necessário apontar que, nessa busca, mostrou-se ausente a produção proveniente de Programas de Pós-Graduação em Educação Profissional, como o do IFRN. Como resultado, evidenciou-se a carência de pesquisas em ambos os campos, sendo encontrados 71 estudos em educação e trabalho, e apenas 10 no campo do financiamento da educação profissional. Assim, pode-se dizer que, ainda que ocorra, a pesquisa nesses campos se dá em um baixo volume.

Palavras-chave: Produção do conhecimento. Educação e trabalho. Financiamento da educação profissional. Programas de pós-graduação.

\section{EDUCATION AND LABOR AND FINANCING OF PROFESSIONAL EDUCATION IN BRAZIL: A MAPPING OF KNOWLEDGE PRODUCTION}

\begin{abstract}
This paper aims to analyze and quantify the production of knowledge in education and labor, and financing of professional education, in Postgraduate Programs. To this end, a mapping of production was carried out through the Brazilian Digital Library of Theses and Dissertations, with inquiries being made from the "subject" field. It is necessary to point out that, in this search, the production from Postgraduate Programs in Professional Education, such as the one in IFRN, was shown to be absent. As a result, there was a lack of research in both fields, with 71 studies in education and labor, and only 10 in the field of professional education financing. Thus, it can be said that, even though it occurs, research in these fields takes place at a low volume.
\end{abstract}

Keywords: Knowledge production. Education and labor. Financing of professional education. Postgraduate programs.

\section{INTRODUÇÃO}


Ao contrário dos demais animais, que agem instintivamente e se adaptam ao meio em que vivem, os seres humanos são capazes de transformar a natureza e, assim, modificá-la para atender as suas próprias necessidades. Tal ação, denominada de trabalho, se constitui como um elemento intrínseco do homem, imperativo para sua existência (FRIGOTTO, 2001). Praticado desde a origem humana, o trabalho exercido pelos primeiros homens sobre a terra, bem como a socialização entre eles, os educava durante o próprio processo. Ao reproduzir esse movimento, as gerações seguintes eram educadas (SAVIANI, 1994).

Desse modo, o trabalho acontecia, inicialmente, de forma em comum, não havendo qualquer separação de castas. Isso muda quando o homem se fixa na terra, tornando-a privada e tornando ele o detentor do meio de produção, dando origem às classes de proprietários e não proprietários. Despidos de qualquer propriedade material, os sujeitos não proprietários são considerados proprietários somente de sua própria força de trabalho (SAVIANI, 1994).

Assim, conforme Frigotto (2001), o trabalho passa a se acondicionar a um modelo de produção que coloca aqueles que são proprietários dos meios de produção, e logo não precisam trabalhar para viver, em uma relação assimétrica com os sujeitos não proprietários, sendo esses os que "necessitam vender sua força de trabalho para sobreviver" (FRIGOTTO, 2001, p. 75). Colocado desta forma, o trabalho perde o protagonismo nos processos de produção da realidade humana, e torna-se moeda de troca, viabilizando a acumulação proposta pelo atual modelo capitalista de produção (FRIGOTTO, 2001).

Nesse sentido, surge, na década de 1960, a chamada "teoria do capital humano", a partir da qual a educação passa a ser compreendida como fundamental para o crescimento da economia, visto que sua capacidade de qualificar os trabalhadores traz maior eficácia à ação do trabalho (SAVIANI, 1994). É nesse contexto que desponta a educação profissional.

No Brasil, essa modalidade de ensino foi originalmente concebida a partir de um viés assistencialista, que tinha como função atender a jovens e crianças, órfãos e abandonados, em instituições de ensino primário, onde aprendiam uma diversidade de ofícios e garantiam, assim, uma função na sociedade. Assim, mantinha-se a ordem, na medida em que diminuíam-se os índices de criminalidade (MOURA, 2007).

Posteriormente, a chegada do século XX trouxe consigo a necessidade por profissionais qualificados para atuar nos âmbitos industrial e da agricultura, dando origem a esforços para estabelecer, no país, uma educação que proporcionasse a formação profissional. Assim, a finalidade da educação profissional viu-se transformada, perdendo o caráter assistencialista e migrando suas atenções para a "preparação de operários para o exercício profissional” (MOURA, 2007, p. 6). 
Assim, como destaca Moura (2008), no decorrer de sua trajetória histórica, a educação recebeu uma configuração dual, sendo ofertada em uma versão científica à elite, centrada nas letras e nas artes, em detrimento da educação profissional, de cunho instrumental, oferecida à população mais pobre. Vinculada ao sistema capitalista de produção, a formação profissional dessa população culminou na gênese de um grande contingente de trabalhadores, o que serviu para conservarem-se baixos os salários dos empregados, visto a grande oferta de mão de obra.

Ainda de acordo com o autor, porém,

\begin{abstract}
Apesar dessa dura realidade, existe outro tipo de sociedade que pode ser buscada. Uma sociedade que tenha o ser humano e suas relações com a natureza, por meio do trabalho, como centro e na qual a ciência e a tecnologia estejam submetidas a uma racionalidade ética ao invés de estarem, quase exclusivamente, a serviço do mercado e do fortalecimento dos indicadores econômicos (MOURA, 2008, p. 26).
\end{abstract}

$\mathrm{Na}$ realidade supracitada, o homem deixa de ser visto como mero instrumento do mercado e passa a ser formado integralmente, de modo a agir ativamente na sociedade, modificando-a a partir de sua participação como sujeito crítico, autônomo, social e político. Em tal conjuntura, é formado, a partir dos fundamentos da educação para o trabalho, um indivíduo capaz de arguir sobre a legitimidade de preceitos impostos pela sociedade, detentor, assim, das condições necessárias para reagir a eles (MOURA, 2008).

Desse modo, ainda que mantenha 0 desígnio de formar a classe trabalhadora para ocupar postos necessários ao desenvolvimento econômico, a educação profissional, que tem o trabalho como princípio educativo, busca proporcionar, a partir de uma formação humanizadora e emancipadora, o pleno desenvolvimento dos indivíduos, tendo como alicerce "valores e práticas ética e culturalmente elevadas, com base nas ciências, nas tecnologias, nas letras, nas artes, na valorização do trabalhador e de uma vida digna para todos, o que significa, também, com uma visão política da própria realidade" (CIAVATTA, 2015, p. 31).

Sendo o trabalho, em seu sentido ontológico, necessário à vida, esse torna-se tanto um dever, no sentido de ser socializado e apreendido através da educação, como também um direito, uma vez que fornece os artifícios para a produção e reprodução da realidade física, biológica, social e cultural dos indivíduos (FRIGOTTO, 2001). Desse modo, "impedir o direito ao trabalho, mesmo em sua forma de trabalho alienado sob o capitalismo, é uma violência contra a possibilidade de produzir minimamente a vida própria" (FRIGOTTO, 2001, p. 74). 
Assim, conforme Castro (2001), no Brasil, a educação é tida como um direito. Compartilhando a obrigação de oferecer aos indivíduos a educação necessária para desenvolver a ação do trabalho, estão a União, os Estados, o Distrito Federal e os Municípios. Tal encargo foi atribuído pela Constituição Federal de 1988, bem como pela Lei de Diretrizes e Bases da Educação Nacional, de 1996, que situou, assim, três sistemas públicos de ensino, que funcionam em regime de colaboração entre os citados entes federados. Dessa forma, cada um dos entes federados possui um sistema de ensino para sustentar e ampliar, o que demanda "mecanismos e fontes de recursos para o seu financiamento" (CASTRO, 2001, p. 12).

No país, a configuração estabelecida para o financiamento da educação, regulamentada pela citada Constituição, determina que a União destine $18 \%$ da receita líquida de impostos para o investimento em educação. Os estados e municípios, por sua vez, ficam obrigados a direcionar, para esse mesmo fim, $25 \%$ de suas arrecadações, ficando estabelecidas ainda outras fontes de financiamento, como a contribuição social coletada pelas empresas, chamada salário-educação (FERREIRA, 2014).

Segundo Cruz \& Jacomini (2017), a importância do financiamento da educação se constitui pela influência central que esse exerce na concretização do direito à educação, no sentido de assegurar, a partir do provimento dos recursos necessários, a garantia ao conferido pela Constituição. Assim, o financiamento se caracteriza como um "aspecto relevante da política educacional, consistindo em condição para viabilizar ações governamentais que assegurem o direito à educação" (CRUZ; JACOMINI, 2017, p. 350).

Isto posto, a relação entre trabalho e educação, dada a concepção humanizadora da educação profissional, e os mecanismos de financiamento da educação profissional no Brasil, configuram-se como importantes campos de estudo. Surgiu, assim, como inquietação, a seguinte questão norteadora: qual a produção acadêmica sobre a relação entre educação e trabalho, e o financiamento da educação profissional, no âmbito dos Programas de PósGraduação brasileiros?

Para responder à questão motivadora da pesquisa, faz-se necessário realizar um estudo bibliométrico, sendo este capaz "de representar a produção do conhecimento científico, a partir da produção científica, e [...] detectar as evidências do desenvolvimento da área estudada, tanto no aspecto epistemológica, quanto teórica" (MARTINS; MEDEIROS NETA; NASCIMENTO, 2019, p. 3).

Desse modo, o presente estudo, que integra uma Dissertação de Mestrado no Programa de Pós-Graduação em Educação Profissional (PPGEP), do Instituto Federal de Educação, Ciência e Tecnologia do Rio Grande do Norte (IFRN) - Campus Natal Central, objetiva analisar e quantificar, na esfera dos Programas de Pós-Graduação brasileiros, a produção do 
conhecimento que trata de duas diferentes categorias: a relação entre educação e trabalho (a), e o financiamento da educação profissional $(b)$.

Para tanto, fez-se um levantamento através do banco de dados da Biblioteca Digital Brasileira de Teses e Dissertações (BDTD) (https://bdtd.ibict.br/), sendo realizadas consultas a partir do campo "assunto". Para a busca das teses e dissertações, dadas as dimensões acima referidas, foram utilizados, entre aspas, os seguintes descritores: para a categoria a, "educação e trabalho", e "relação entre educação e trabalho"; e para a categoria $b$, "financiamento da educação" e "financiamento da educação profissional".

Não sendo demarcado qualquer recorte temporal no processo de busca, foram considerados todos os resultados apresentados. No intuito de analisar a coerência entre o título dos trabalhos encontrados e os objetos de estudo em questão, foi feita a leitura cuidadosa dos resumos das teses e dissertações, e então selecionadas e quantificadas aquelas que tratavam dos escopos préestabelecidos por esta pesquisa.

Desse modo, este estudo se organiza da presente forma: uma introdução, um item que apresenta a configuração da produção acadêmica em educação e trabalho e financiamento da educação no Brasil, os resultados, que apresentam a quantificação desses trabalhos no âmbito dos Programas de Pós-Graduação brasileiros, e, por fim, as considerações finais, que arrematam as ideias discutidas.

\section{EDUCAÇÃO E TRABALHO E FINANCIAMENTO DA EDUCAÇÃO ENQUANTO CAMPOS DE ESTUDO}

Desde o século anterior, a relação entre educação e trabalho se constitui como tema de pesquisas acadêmicas (CIAVATTA, 2015). Assim, de acordo com Moraes (2015, p. 91), a partir da década de 1950, o campo de produção científica, batizado pelos estudiosos "como o das relações ou 'vínculos' entre educação e economia, entre formação e emprego, ou entre 'sistema educativo e sistema produtivo'", se estabeleceu, no mundo, como uma importante área de estudo.

No Brasil, a produção do conhecimento em educação iniciou-se em uma conjuntura na qual estavam sendo implementadas as políticas educacionais propostas pelo governo militar. Provindas principalmente de programas norte-americanos, devido ao pequeno número de cursos de pósgraduação instituídos no país, as pesquisas da área apresentavam, como característica, o forte cunho crítico, inspirado principalmente pelo ideário marxista (HANDFAS, 2007).

Com o intuito de conhecer e reconhecer as ligações entre educação e trabalho, estabelecidas pela ideologia capitalista, onde a escola se torna uma 
ferramenta para a formação da mão de obra necessária ao sucesso do sistema, as pesquisas que tinham tal objeto de estudo carregavam consigo a forte influência da teoria do capital humano, e buscavam, a partir do presente nas obras desses teóricos, "o embasamento para a fundamentação, cuja hipótese central era formulada a partir da relação entre educação e desenvolvimento econômico e social" (HANDFAS, 2007, p. 386).

Desse modo, constituindo-se como campo de estudo acerca das relações entre o trabalho e o capital, as modificações nos cenários político e socioeconômico devem também ser consideradas e analisadas (TREIN; CIAVATTA, 2003). Diante disso, esse campo possui, como grande desafio, a integração de "conhecimentos que se desenvolvem de forma isolada nas instituições acadêmicas de ensino e pesquisa" (MORAES, 2015, p. 91), estando entre estes a economia, a sociologia do trabalho e a história da educação.

A partir desse escopo, desdobram-se as discussões sobre a Educação Profissional, uma vez que esta interliga-se diretamente à formação para o trabalho, dada pela necessidade da mão de obra qualificada exigida pelo mercado. Enquanto área de pesquisa, a educação profissional se constitui como campo que agrega estudos acerca de diferentes recortes da educação profissional, situada como modalidade de ensino (MEDEIROS NETA, 2016). Um desses recortes é o financiamento da educação profissional.

Como campo de estudo, o financiamento da educação é um que também se destaca. Sua relevância pode ser observada a partir do crescente volume de estudos acadêmicos sobre a temática, principalmente no âmbito dos programas de pós-graduação (CRUZ; JACOMINI, 2017), que têm apresentado pesquisas que buscam a reflexão sobre os investimentos realizados em educação tanto pelo setor público, quanto aqueles financiados pelo setor privado (CASTRO, 2001).

No que concerne as discussões acerca do financiamento da educação, de acordo com Castro (2001, p. 11), essas "tem a ver com as condições materiais e com os recursos financeiros que viabilizam a formulação, implementação e avaliação das políticas" elaboradas para tal finalidade. Quando analisado a partir de um viés jurídico-institucional, porém, o estudo "implica a análise da esfera fiscal, cobrindo as características e o desenrolar histórico das principais fontes de financiamento tributário, assim como as contribuições sociais e demais fontes que se destinam à área" (CASTRO, 2001, p. 11).

Assim, com a produção acadêmica em financiamento da educação, o que se busca é uma visão panorâmica do cenário fiscal que compete 0 financiamento da área, missão que torna-se mais difícil ao envolver o âmbito privado, visto que, muitas vezes, os dados necessários à pesquisa encontramse indisponíveis, impossibilitando referenciar, nesses estudos, todas as fontes associadas ao financiamento da educação brasileira (CASTRO, 2001). 
Estudos nessa área são responsáveis ainda por principiar e difundir importantes discussões relacionadas às dificuldades enfrentadas pela educação em razão do seu financiamento, evidenciando a necessária expansão de investimentos (CRUZ; JACOMINI, 2017).

\section{RESULTADOS E DISCUSSÃO}

A busca feita na Biblioteca Digital Brasileira de Teses e Dissertações (BDTD), utilizando como descritor o termo "trabalho e educação" apresentou 102 ocorrências. A pesquisa pelo termo "relação educação e trabalho", por sua vez, exibiu 12 resultados. Após a leitura cuidadosa dos resumos e o descarte de resultados duplicados, foram selecionados para compor este estudo, 71 produções acadêmicas que tratam da relação entre educação e trabalho. Desse total, $46(64,7 \%)$ representavam dissertações, defendidas entre os anos de 1997 e 2020, e 25 (35,3\%) eram teses, defendidas no intervalo entre 1987 e 2020. A análise do perfil dos pesquisadores permitiu aferir que, desses estudos, $43(60,5 \%)$ foram produzidos por pesquisadoras do sexo feminino, enquanto 28 (39,5\%) têm, como autor, pesquisadores do sexo masculino.

Quando utilizado "financiamento da educação" como descritor, a pesquisa realizada na BDTD exibiu também 102 resultados. Já a busca feita com o descritor "financiamento da educação profissional" resultou no achado de 12 produções. Feita a leitura dos resumos e o rejeite de ocorrências duplicadas, foram selecionados 81 trabalhos acadêmicos sobre financiamento da educação brasileira. Desses, $58(71,6 \%)$ eram dissertações defendidas entre os anos de 2000 e 2020, e 23 (29,4\%) eram teses, defendidas entre 2001 e 2019. $50(61,7 \%)$ dos estudos possuem, como autoria, pesquisadoras do sexo feminino, enquanto $31(38,3 \%)$ possuem pesquisadores do sexo masculino como autores.

A seguir, serão apresentados os dados que permitirão demonstrar, no âmbito dos Programas de Pós-Graduação brasileiros, qual a produção do conhecimento acerca da relação entre educação e trabalho e do financiamento da educação, em especial da educação profissional, bem como as principais temáticas pesquisadas dentro desses escopos, observadas a partir do objeto de pesquisa de cada estudo.

\subsection{PRODUÇÃO EM EDUCAÇÃO E TRABALHO}

Apresentada pelo Gráfico 1, está a produção do conhecimento acerca da relação entre educação e trabalho, feita ano a ano. Os resultados apresentados pela busca realizada na BDTD permitem observar quão tímida tem sido a produção do conhecimento sobre o campo de pesquisa.

Ainda assim, vê-se que este aparece, no âmbito dos Programas de PósGraduação, como objeto de pesquisa desde o ano de 1987, quando foi 
encontrada 1 produção acerca da temática, número que persistiu nos anos de 1997, 1999, 2001, 2003 e 2005. A partir do ano de 2006, porém, há um salto no número de teses e dissertações defendidas, que passaram para 4, naquele ano e nos anos de 2007, 2009, 2010 e 2012. Os anos de destaque na produção do conhecimento em educação e trabalho foram 2015 e 2017, sendo 9 o número de defesas de teses e dissertações nesses anos.

Gráfico 1. Produção anual do conhecimento em educação e trabalho.

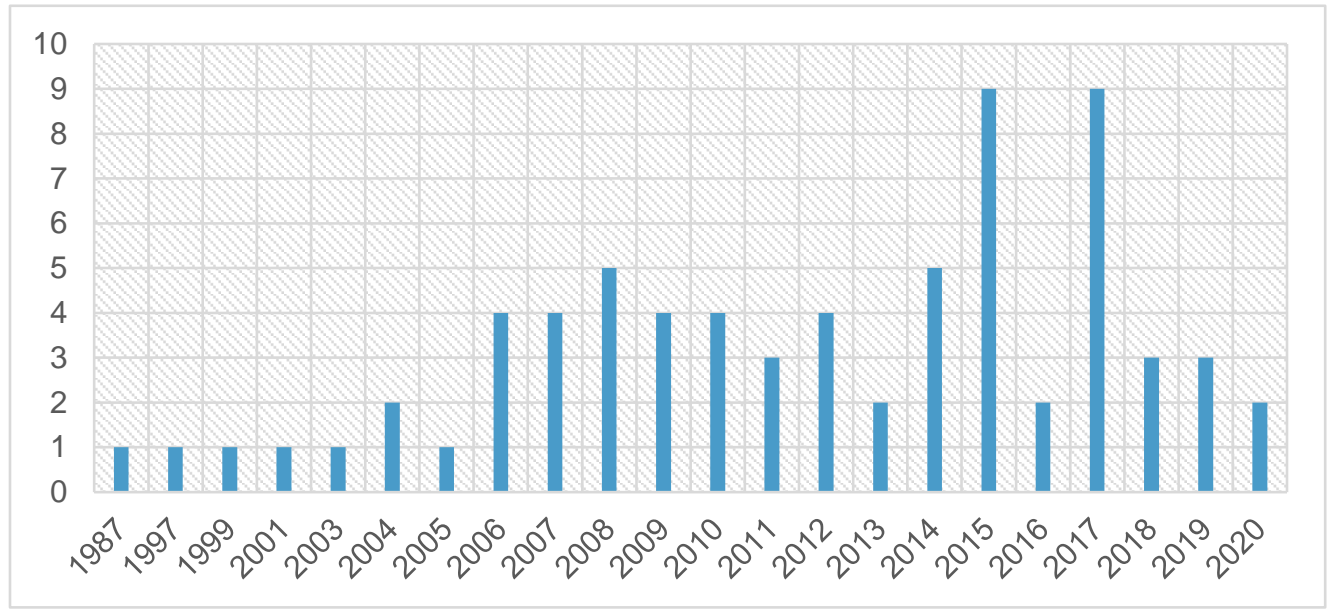

Fonte: elaborado pelos autores (2020).

Ainda que, na série histórica, não se repitam os números observados no ano de 2005 e em anos anteriores, torna-se visível a escassez de estudos produzidos no âmbito dos Programas de Pós-Graduação acerca da relação entre educação e trabalho.

Gráfico 2. Instituições de Ensino das Defesas.

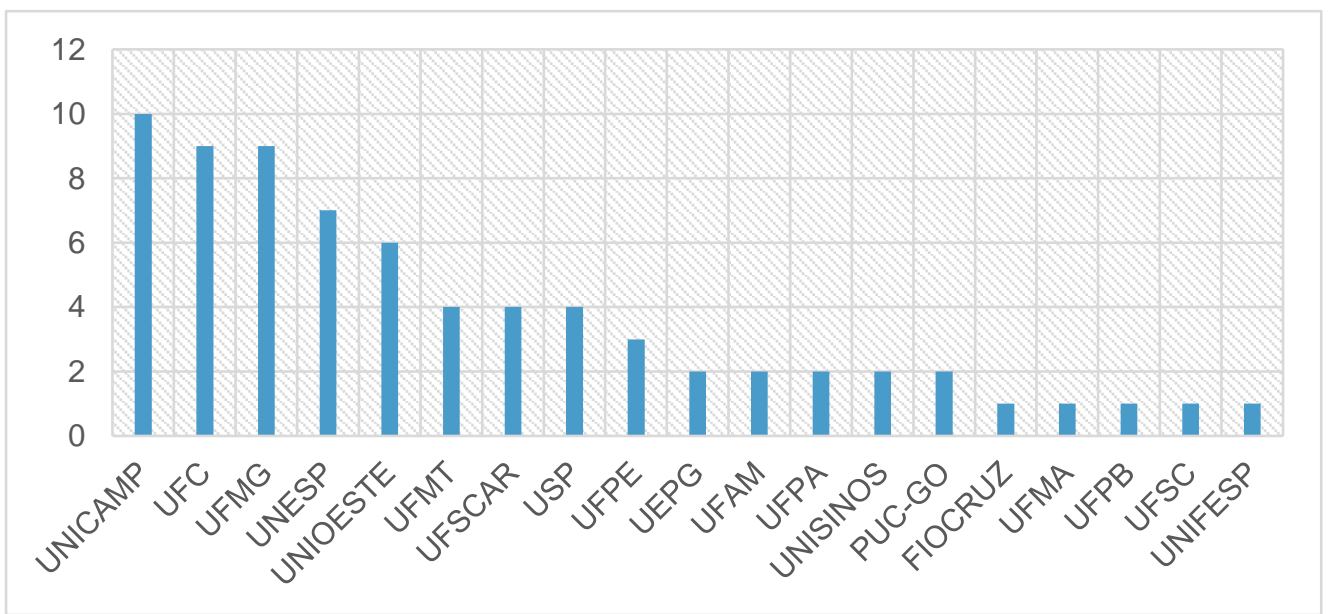

Fonte: elaborado pelos autores (2020). 
O Gráfico 2 mostra onde se concentra a produção do conhecimento acerca do campo de estudo em questão. A partir do expresso, é possível perceber que figuram, como principais instituições produtoras, a Universidade Estadual de Campinas (UNICAMP), com 10 trabalhos; a Universidade Federal do Ceará (UFC), com 9 defesas; a Universidade Federal de Minas Gerais (UFMG), também com 9 produções; a Universidade Estadual Paulista (UNESP), com 7 estudos; e a Universidade Estadual do Oeste do Paraná (UNIOESTE), com 6 teses e dissertações. Juntas, as instituições somam 41 produções, o que representa $57,7 \%$ dos estudos analisados.

É possível também, porém, averiguar que a pesquisa neste campo está presente em pelo menos mais 14 Instituições de Ensino Superior espalhadas pelo país, ainda que ocorrendo em menor escala. São elas: a Universidade Federal de Mato Grosso (UFMT), a Universidade Federal de São Carlos (UFSCAR) e a Universidade de São Paulo (USP), com 4 produções cada; a Universidade Federal de Pernambuco (UFPE), com 3 trabalhos; a Universidade Estadual de Ponta Grossa (UEPG), a Universidade Federal do Amazonas (UFAM), a Universidade Federal do Pará (UFPA), a Universidade do Vale do Rio dos Sinos (UNISINOS) e a Pontifícia Universidade Católica de Goiás (PUC-GO), que contam com 2 teses ou dissertações cada; a Fundação Oswaldo Cruz (FIOCRUZ), a Universidade Federal do Maranhão (UFMA), a Universidade Federal da Paraíba (UFPB), a Universidade Federal de Santa Catarina (UFSC) e a Universidade Federal de São Paulo (UNIFESP), que tiveram apenas 1 defesa cada.

Gráfico 3: Programas de Pós-Graduação.

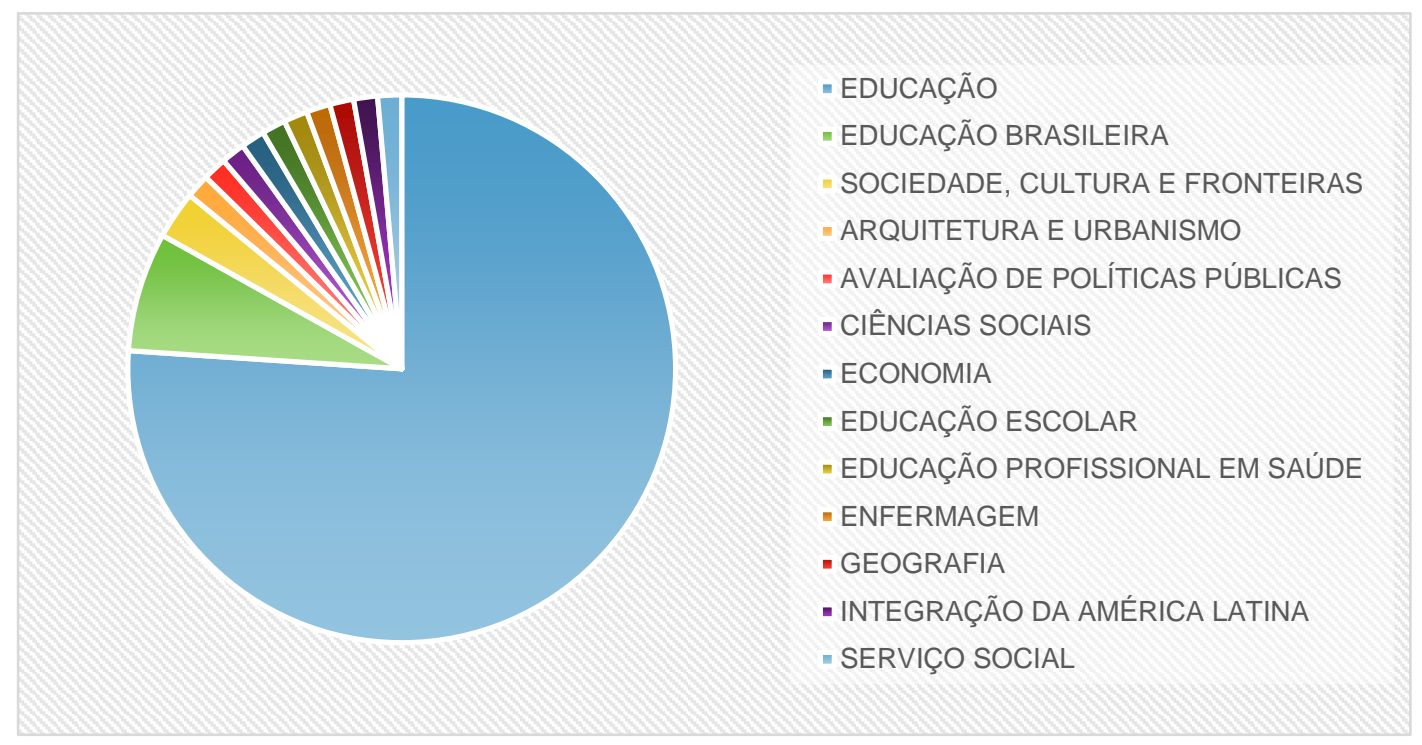

Fonte: elaborado pelos autores (2020).

No Gráfico 3 está posto como a produção do conhecimento neste campo se distribui entre os Programas de Pós-Graduação brasileiros. Como esperado, 
é possível apontar os Programas de Pós-Graduação em Educação como os grandes responsáveis pela produção do conhecimento acerca da relação entre educação e trabalho, acumulando 54 dos 71 estudos analisados, o que representa $76 \%$ da totalidade. Seguindo, vem o Programa de Pós-Graduação em Educação Brasileira, com 5 trabalhos, e o Programa de Pós Graduação em Sociedade, Cultura e Fronteiras, com 2 teses ou dissertações.

O campo de estudo figurou ainda como objeto de pesquisa em mais 10 Programas de Pós-Graduação, que apresentaram, cada um, 1 única produção. Foram eles: Arquitetura e Urbanismo, Avaliação de Políticas Públicas, Ciências Sociais, Economia, Educação Escolar, Educação Profissional em Saúde, Enfermagem, Geografia, Integração da América Latina e Serviço Social.

O Gráfico 4 apresenta a forma como o campo de estudo das relações entre educação e trabalho se estrutura, observada através das ramificações demonstradas pela variedade de perspectivas pesquisadas, vista a partir da análise dos trabalhos encontrados na Biblioteca Digital Brasileira de Teses e Dissertações. Desse modo, no gráfico a seguir, estão listadas, bem como agrupadas em categorias, as temáticas abordadas pelos pesquisadores de Programas de Pós-Graduação em seus estudos.

Gráfico 4. Categorias estudadas no campo.

POLÍTICAS DE FORMAÇÃO PROFISSIONAL INSTITUIÇÕES DE ENSINO PARA O TRABALHO EDUCAÇÃO E MERCADO / CAPITAL

EDUCAÇÃO PARA O TRABALHO NO CAMPO EDUCAÇÃO E TRABALHO INFORMAL / ARTESANAL TRABALHO E FORMAÇÃO TECNOLÓGICA / INDUSTRIAL

TRABALHO COMO PRINCÍPIO EDUCATIVO FORMAÇÃO PARA O TRABALHO E MOVIMENTOS SOCIAIS EDUCAÇÃO POLITÉCNICA EDUCAÇÃO PARA O TRABALHO DE JOVENS E ADULTOS EDUCAÇÃO NO TRABALHO CURRÍCULO DA FORMAÇÃO PROFISSIONAL

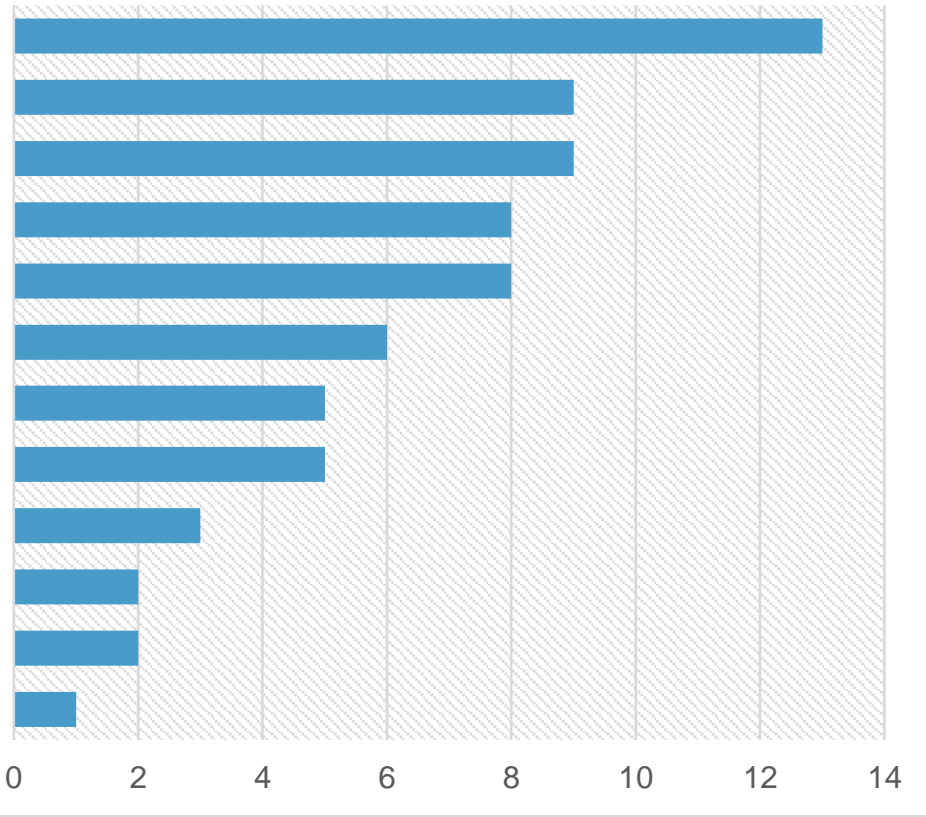

Fonte: elaborado pelos autores (2020).

Como observado, as políticas de formação profissional se apresentam como o mais recorrente tema de pesquisa, sendo 13 o número de estudos acerca das diferentes políticas empregadas para esse fim, representando $18,3 \%$ do total de trabalhos analisados. Em seguida, com 9 teses ou 
dissertações defendidas, estão as produções acerca das Instituições de Ensino Profissional, bem como a relação entre educação e o mercado de trabalho.

Também apresentando um alto número de resultados, a educação direcionada ao trabalho no campo, e a educação relacionada ao trabalho informal ou artesanal foram objeto de estudo de 8 das teses e dissertações produzidas. As relações entre a formação tecnológica e/ou industrial e trabalho foram abordadas em 6 das pesquisas analisadas, e o trabalho como princípio educativo, bem como a formação para o trabalho no âmbito dos movimentos sociais, apareceram em 4. A educação politécnica foi abordada em 3 das produções, e a educação para o trabalho, voltada para o público de jovens e adultos, bem como os processos educativos no âmbito do trabalho, despontaram como objeto em 2 dos estudos. Por último, com apenas 1 pesquisa encontrada, aparece o currículo da formação profissional.

\subsection{FINANCIAMENTO DA EDUCAÇÃO}

A partir do expresso pelo Gráfico 5, é possível observar que a produção do conhecimento, no âmbito dos Programas de Pós-graduação brasileiros, acerca da temática do financiamento da educação, se iniciou de forma tímida, com apenas um trabalho defendido nos anos de 2000, 2001, 2002 e 2003. O cenário começa a mudar a partir do intervalo entre os anos de 2005 e 2008, quando 3 estudos sobre a temática foram realizados em cada ano e, mais expressivamente, em 2009 e 2010, quando 5 teses e dissertações foram produzidas por ano. $O$ ano de menor produção foi o de 2004, não sendo encontrado qualquer estudo sobre a temática nesse período. Já os anos de maior produção foram os de 2011, com 8; 2015, com 9; e 2018, com 8 teses ou dissertações defendidas, somando 25 produções, ou $30,8 \%$ do total.

Gráfico 5: Produção anual do conhecimento em financiamento da educação.

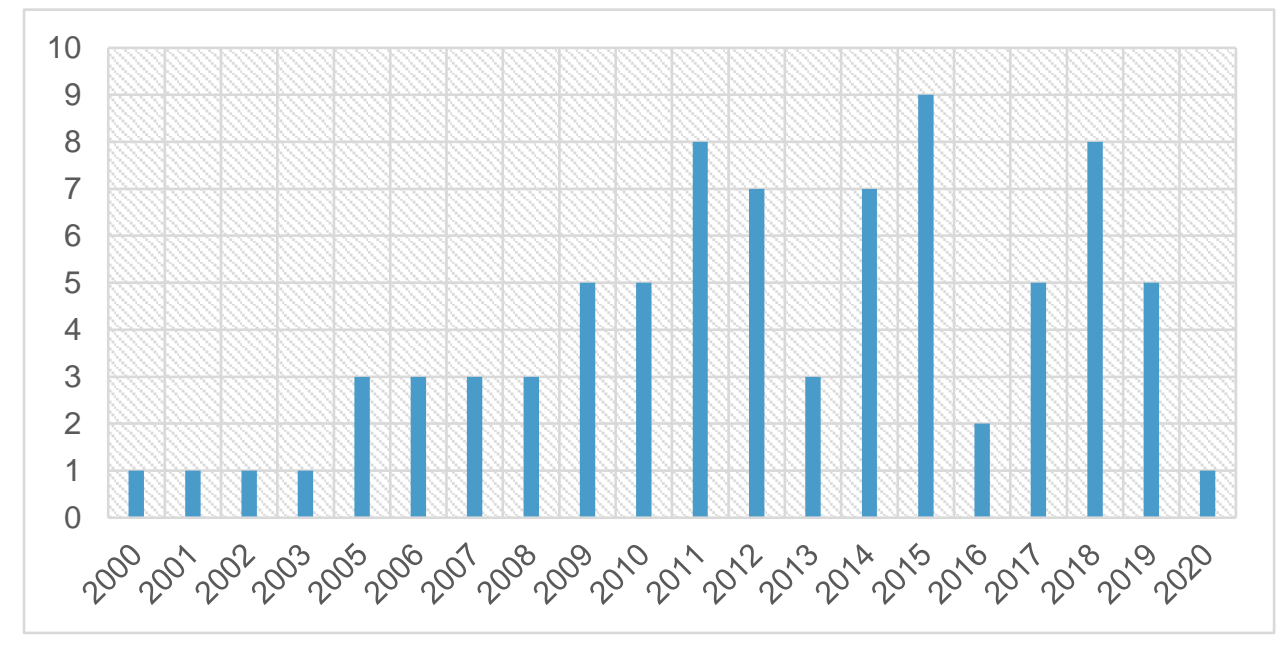

Fonte: elaborado pelos autores (2020). 
Ainda que a produção do conhecimento acerca do financiamento da educação tenha oscilado no decorrer dos últimos anos, é possível perceber a tendência de crescimento no número de estudos realizados, uma vez que voltou-se ao patamar estabelecido entre os anos de 2000 e 2004 apenas no ano de 2020, que está em curso durante a produção deste trabalho.

Com o presente no Gráfico 6, é possível analisar como a produção do conhecimento acerca do financiamento da educação se distribui entre as diferentes Instituições de Ensino Superior. Foram encontradas produções em 26 universidades distintas, sendo possível observar que a Universidade Federal do Rio Grande do Sul (UFRGS), com 14 produções; a Universidade de São Paulo (USP) também com 14; a Universidade Federal do Pará (UFPA), com 8; a Universidade Federal de Goiás (UFG), com 5; e a Universidade Estadual de Campinas (UNICAMP), com 4, compartilham, entre si, 45 dos estudos realizados, o que representa $55,5 \%$ do total de trabalhos analisados.

Gráfico 6. Instituições de Ensino das Defesas.

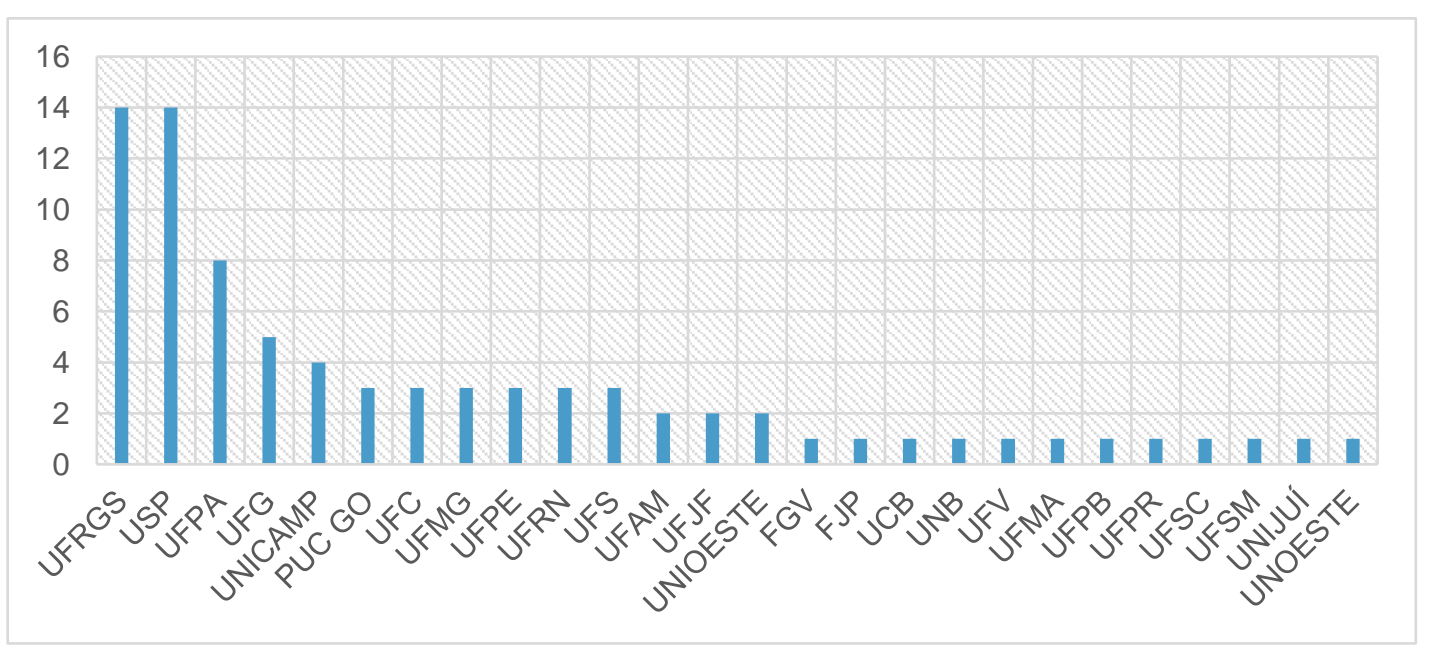

Fonte: elaborado pelos autores (2020).

Ainda assim, pode se dizer que estudos dessa natureza são produzidos, mesmo que mais timidamente, no âmbito dos Programas de Pós-Graduação do país inteiro, uma vez que 21 outras Instituições de Ensino Superior dividem, entre si, 36 dos trabalhos defendidos, o que representa $44,5 \%$ do todo.

São elas: a Pontifícia Universidade Católica de Goiás (PUC-GO), a Universidade Federal do Ceará (UFC), Universidade Federal de Minas Gerais (UFMG), Universidade Federal de Pernambuco (UFPE), Universidade Federal do Rio Grande do Norte (UFRN) e Universidade Federal de Sergipe (UFS), onde foram produzidos 3 trabalhos; a Universidade Federal do Amazonas (UFAM), a Universidade Federal de Juiz de Fora (UFJF) e a Universidade Estadual do Oeste do Paraná (UNIOESTE), onde defendeu-se 2 estudos; com apenas uma produção, aparecem a Fundação Getúlio Vargas (FGV), Universidade Católica de Brasília (UCB), Universidade de Brasília (UNB), 
Universidade Federal de Viçosa (UFV), Universidade Federal do Maranhão (UFMA), Universidade Federal da Paraíba (UFPB), Universidade Federal do Paraná (UFPR), Universidade Federal de Santa Catarina (UFSC), Universidade Federal de Santa Maria (UFSM), Universidade Regional do Noroeste do Estado do Rio Grande do Norte (UNIJUÍ) e a Universidade Estadual do Oeste Paulista (UNOESTE).

O Gráfico 7 mostra em quais Programas de Pós-Graduação concentram-se os estudos sobre o financiamento da educação. Como é possível observar, os Programas de Pós-Graduação em Educação são os grandes produtores de conhecimento acerca da temática, acumulando 69 das 81 teses e dissertações analisadas, o que representa $85,1 \%$ do total.

Gráfico 7. Programas de Pós-Graduação.

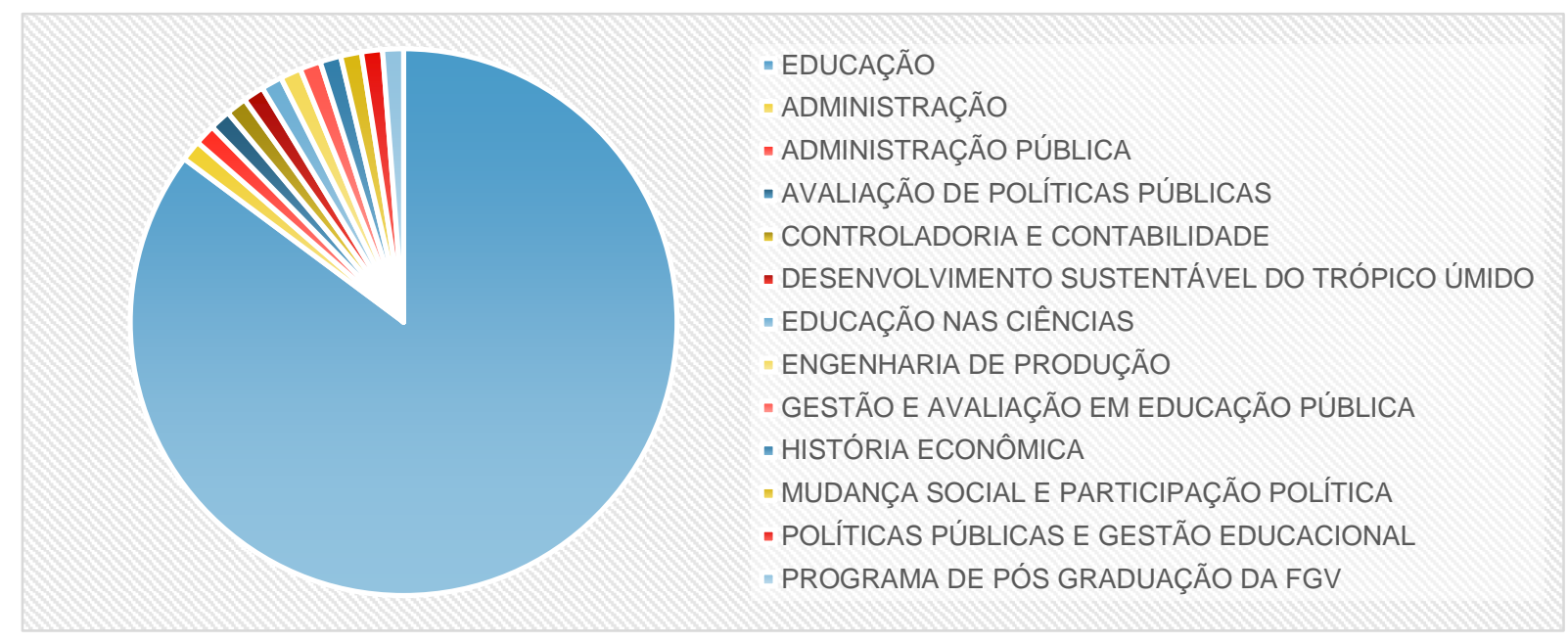

Fonte: elaborado pelos autores (2020).

Ainda assim, é possível notar que essa área de conhecimento não se restringe aos Programas de Pós-Graduação em Educação, uma vez que foram encontrados mais 12 estudos, que tratam dessa temática, distribuídos entre 12 programas diferentes. Estão entre eles: o Programa de Pós-Graduação em Administração, Administração Pública, Avaliação de Políticas Públicas, Controladoria e Contabilidade, Desenvolvimento Sustentável do Trópico Úmido, Educação nas Ciências, Engenharia de Produção, Gestão e Avaliação em Educação Pública, História Econômica, Mudança Social e Participação Política, Políticas Públicas e Gestão Educacional e no Programa de PósGraduação da Fundação Getúlio Vargas.

No Gráfico 8, é possível observar como o campo de estudo da política de financiamento da educação se debruça sobre as mais diferentes perspectivas da educação brasileira. Assim, encontram-se dispostos, no seguinte gráfico, as categorias abordadas em estudos relativos ao aspecto do financiamento da educação, realizados no âmbito dos Programas de Pós- 
Graduação brasileiros, de acordo com o levantamento feito na Biblioteca Digital Brasileira de Teses e Dissertações.

Gráfico 8. Categorias estudadas no campo.

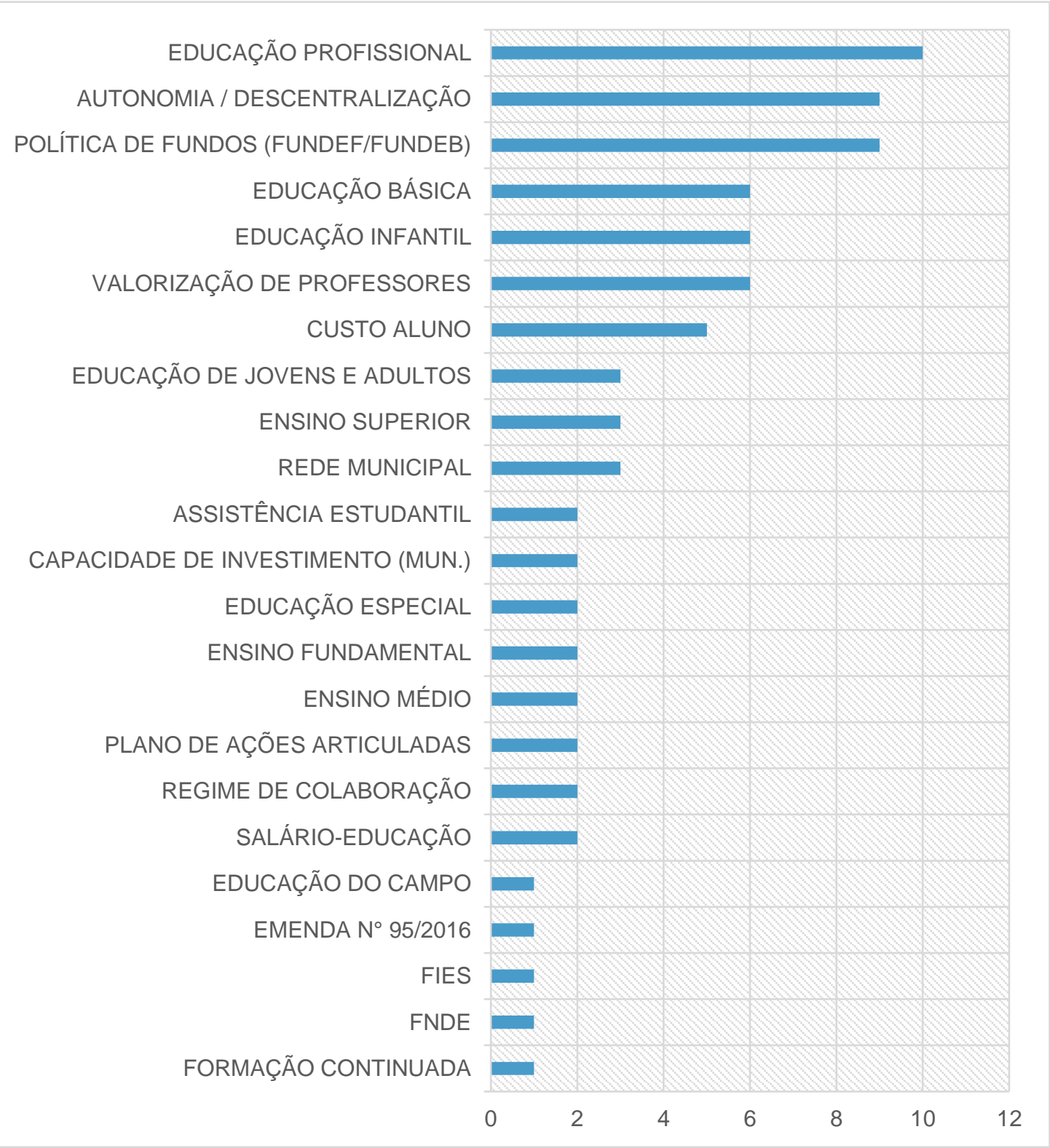

Fonte: elaborado pelos autores (2020).

Como é possível perceber, o financiamento da educação profissional figura como o mais recorrente objeto de estudo apresentado pela busca, com 10 resultados encontrados, o que representa $12,3 \%$ do total de trabalhos analisados. Tal decorrência pode dever-se, porém, ao descritor "financiamento da educação profissional", utilizado no momento da pesquisa realizada na BDTD. Ainda que se apresente como o viés mais estudado quando se trata de financiamento da educação, a produção sobre o campo, em Programas de 
Pós-Graduação ainda se mostra escassa. Estão apresentados a seguir, na Tabela 1, as produções encontradas.

Tabela 1. O Conhecimento em financiamento da Educação Profissional

\begin{tabular}{|c|c|c|c|c|}
\hline TIPO & TÍTULO & INSTITUIÇÃO & PROGRAMA & ANO \\
\hline Dissertação & $\begin{array}{l}\text { O PROEM e seus vínculos com o BID/BIRD: os } \\
\text { motivos financeiros e as razões ideológicas da } \\
\text { política educacional paranaense para o ensino } \\
\text { médio e profissional (1995-1999) }\end{array}$ & UNICAMP & Educação & 2000 \\
\hline Dissertação & $\begin{array}{c}\text { O financiamento dos Centros Federais de } \\
\text { Educação Tecnológica: o caso do CEFET-PR } \\
\text { no período } 1989-2001\end{array}$ & UFSC & $\begin{array}{l}\text { Engenharia de } \\
\text { Produção }\end{array}$ & 2002 \\
\hline Tese & O capital financeiro e a educação no Brasil & UNICAMP & Educação & 2005 \\
\hline Tese & $\begin{array}{c}\text { Financiamento da educação profissional no } \\
\text { Brasil: contradições e desafios }\end{array}$ & UFRGS & Educação & 2010 \\
\hline Dissertação & $\begin{array}{c}\text { Financiamento e educação profissional: análise } \\
\text { do Programa Brasil Profissionalizado no estado } \\
\text { do Pará }\end{array}$ & UFPA & Educação & 2012 \\
\hline Dissertação & $\begin{array}{l}\text { Financiamento da política pública para a } \\
\text { educação profissional no Estado do Paraná } \\
\text { (2003-2012) }\end{array}$ & UNIOESTE & Educação & 2013 \\
\hline Dissertação & $\begin{array}{l}\text { Gestão financeira da política de ensino médio } \\
\text { integrado e integral do Ceará }\end{array}$ & UFJF & $\begin{array}{c}\text { Gestão e } \\
\text { Avaliação em } \\
\text { Educação Pública }\end{array}$ & 2014 \\
\hline Dissertação & $\begin{array}{l}\text { Implementação da política de educação } \\
\text { profissional ofertada pela rede E-TEC no brasil } \\
(2011-2015)\end{array}$ & UNIOESTE & Educação & 2015 \\
\hline Dissertação & $\begin{array}{l}\text { O Plano Nacional de Qualificação Profissional } \\
\text { no Pará: um estudo a partir da Resolução № } \\
\text { 333/2003 do CODEFAT }\end{array}$ & UFPA & Educação & 2017 \\
\hline Tese & $\begin{array}{c}\text { O financiamento da Rede Federal de Educação } \\
\text { Profissional, Científica e Tecnológica }\end{array}$ & UFG & Educação & 2018 \\
\hline
\end{tabular}

Fonte: Elaborado pelos autores (2020).

Dos estudos analisados, 5 foram escritos por pesquisadoras do sexo feminino, e 5, por pesquisadores do sexo masculino. A pesquisa se concentra em Programas de Pós Graduação em Educação (80\%), e ocorre em diferentes instituições, destacando-se a Universidade Estadual de Campinas (UNICAMP), 
a Universidade Estadual do Oeste do Paraná (UNIOESTE) e a Universidade Federal do Pará (UFPA), que detém $60 \%$ das produções.

Como visto na Tabela 1, a produção acerca do financiamento da Educação Profissional começa a se intensificar em Programas de PósGraduação a partir da década de 2010, quando foram defendidas 5 dissertações e 1 tese no intervalo entre os anos de 2012 e 2018. Nesse sentido, não há qualquer concentração quanto as temáticas abordadas pelas produções, sendo observados diversos objetos de pesquisa.

A seguir, entre as temáticas mais comumente pesquisadas por estudiosos do financiamento da educação, estão: com 9 estudos encontrados, a autonomia escolar e a descentralização de recursos, dada através de programas como o Dinheiro Direto na Escola (PDDE); a política de fundos, usualmente representada pelo estudo do FUNDEF e do FUNDEB, também com 9 produções; aparecem, com 8 trabalhos, as pesquisas acerca do financiamento da educação básica em sua totalidade; o financiamento da educação infantil; e as políticas de valorização dos professores; atrás, com 5 pesquisas defendidas, vem a temática do custo aluno.

São várias as perspectivas estudadas em financiamento da educação, ainda que em menor proporção. São elas: o financiamento da Educação de Jovens e Adultos; o financiamento do ensino superior; e o financiamento da rede municipal de ensino, com 3 resultados; aparecem como objeto de estudo em 2 pesquisas, o financiamento de programas referentes à assistência estudantil, como alimentação e transporte escolar; a capacidade de investimento em educação dos municípios; o financiamento da educação especial, direcionada a educandos com deficiência, transtornos globais do desenvolvimento e altas habilidades ou superdotação; o financiamento do ensino fundamental; o financiamento do ensino médio; o Plano de Ações Articuladas; o regime de colaboração entre os entes federados; e o salárioeducação.

Apresentaram apenas 1 resultado os estudos sobre o financiamento da educação do campo; as implicações da Emenda $n^{\circ}$ 95/2016 para o financiamento da educação; o Financiamento ao Estudante do Ensino Superior (FIES); o Fundo Nacional de Desenvolvimento da Educação (FNDE); e o financiamento da formação continuada, prestada aos professores e demais profissionais da educação.

\section{CONSIDERAÇÕES FINAIS}

Diante dos achados proporcionados por este estudo, torna-se evidente a carência de pesquisas no âmbito das relações entre trabalho e educação, uma vez que foram encontrados, em pesquisa, apenas 71 estudos neste campo. Essa deficiência se repete em relação ao campo do financiamento da 
educação, dada a pequena dimensão de estudos encontrados, que somaram apenas 81 .

Em se tratando especificamente do financiamento da educação profissional, a insuficiência de estudos torna-se ainda mais acentuada, uma vez que foram encontrados apenas 10 estudos sobre a temática. Assim, é possível dizer que, ainda que a pesquisa ocorra no âmbito dos Programas de Pós-Graduação, ela acontece em um baixo volume. Dada a vasta quantidade de objetos estudados, em contrapartida, é grande também a lacuna existente.

Isto posto, se torna necessário apontar que, na busca realizada através da Biblioteca Digital Brasileira de Teses e Dissertações, mostrou-se ausente a produção proveniente de Programas de Pós-Graduação em Educação Profissional, como o presente no Instituto Federal de Educação, Ciência e Tecnologia do Rio Grande do Norte - Campus Natal Central, o que pôde contribuir negativamente para o baixo número de estudos encontrados.

\section{REFERÊNCIAS}

CASTRO, João Abrahão de. Financiamento da Educação no Brasil. Em Aberto, Brasília, v. 18, n. 74, p. 11-32, dez. 2001.

CIAVATTA, Maria. O percurso histórico do GT Trabalho e Educação - um exercício de interpretação. Revista Trabalho Necessário, Niterói, v. 13, n. 20 , p. 22-50, 2015.

CRUZ, Rosana Evangelista da; JACOMINI, Márcia Aparecida. Produção Acadêmica sobre financiamento da educação: 2000-2010. Revista Brasileira de Estudos Pedagógicos, Brasília, v. 98, n. 249, p. 347-370, maio/ago. 2017.

FERREIRA, Maria Aparecida dos Santos. O FUNDEF e o FUNDEB como política de financiamento para a valorização do magistério: efeitos na carreira e na remuneração dos professores da rede pública estadual de ensino do RN. 2014, 353 f. Tese (Doutorado em Educação) - Universidade Federal do Rio Grande do Norte, Natal, 2014. Disponível em: $<$ https://repositorio.ufrn.br/jspui/bitstream/123456789/19286/1/FUNDEFeFUN DEBPol\%C3\%ADtica Ferreira 2014.pdf>. Acesso em: 04 jul. 2020.

FRIGOTTO, Gaudêncio. Educação e Trabalho: bases para debater a Educação Profissional Emancipadora. Perspectiva, Florianópolis, v. 19, n. 1, p. 71-87, jan./jun. 2001.

HANDFAS, Anita. A trajetória do GT Trabalho e Educação da ANPED: alguns elementos de análise. Trabalho, Educação e Saúde, Rio de Janeiro, v. 5, n. 3, p. 375-398, nov. 2007/fev. 2008.

MARTINS, Jéssica Souza; MEDEIROS NETA, Olivia Morais de; NASCIMENTO, Francinaide de Lima Silva. O Catálogo de Teses e 
Dissertações como fonte para estudos bibliométricos do campo da Educação Profissional. Research, Society and Development, Vargem Grande Paulista, v. 8 , n. 8, p. 1-17, maio 2019.

MEDEIROS NETA, Olivia Morais de. A configuração do campo da Educação Profissional no Brasil. Holos, Natal, v. 6, p. 50-55, out. 2016.

MORAES, Carmen Sylvia Vidigal. Trabalho e educação como pauta do GT Trabalho e Educação da ANPED: algumas considerações sobre o campo de pesquisa. Revista Trabalho Necessário, Niterói, v. 13, n. 20, p. 88-118, 2015.

MOURA, Dante Henrique. A Educação Básica e Educação Profissional e Tecnológica: dualidade histórica e perspectivas de integração. Holos, Natal, v. 2, p. 4-30, 2007.

MOURA, Dante Henrique. A formação de docentes para a Educação Profissional e Tecnológica. Revista Brasileira da Educação Profissional e Tecnológica, Natal, v. 1, n. 1, p. 23-38, 2008.

SAVIANI, Dermeval. O trabalho como princípio educativo frente às novas tecnologias. In: FERRETI, C. J. et al. (Orgs.). Novas tecnologias, trabalho e educação. Petrópolis: Vozes, 1994. p. 147-164.

TREIN, Eunice; CIAVATTA, Maria. O percurso teórico e empírico do GT Trabalho e Educação: uma análise para debate. Revista Brasileira de Educação, Rio de Janeiro, n. 24, p. 140-164, set./out./nov./dez. 2003. 